\title{
Processos de educação sexual em cursos de medicina: reflexões sobre a construção do saber médico
}

\author{
Yalin Brizola YARED \\ Sonia Maria Martins de MELO
}

\section{Introdução}

Educação, sexualidade e emancipação parece ser uma tríade utópica no que se refere às interfaces possíveis entre essas categorias. Pelo menos a julgar pelo resultado que se obtém em pesquisas na área da Educação sobre o tema da sexualidade há alguns anos (SANTOS; BRUNS, 2000; NUNES, 2005; FIGUEIRÓ, 2006; MELO; POCOVI, 2008; YARED, 2011). Atualmente, as buscas por indícios da construção de uma abordagem de Educação Sexual emancipatória no ambiente escolar ainda nos levam, na maioria dos casos, a vertentes pedagógicas dessa dimensão humana da sexualidade com características preponderantes de omissão e/ou repressão vivenciadas pelos/as estudantes, professores/as e funcionários/as. Novas concepções de ensino com métodos ativos de aprendizagem e apoio da modernização tecnológica de informaçôes são

1 Bolsista CAPES. Membro do Grupo de Pesquisa: Formação de Educadores e Educação Sexual (EDUSEX) CNPq. Doutoranda em Educação. UDESC Universidade do Estado de Santa Catarina. Centro de Ciências Humanas e da Educação. Florianopolis - SC - Brasil. 88035-001 - yalinbio@gmail.com

2 Líder do Grupo de Pesquisa: Formação de Educadores e Educação Sexual (EDUSEX) CNPq. UDESC - Universidade do Estado de Santa Catarina. Centro de Ciências Humanas e da Educação. Florianopolis - SC - Brasil. 88035-001 - soniademelo@ gmail.com 
incorporados em projetos pedagógicos com propostas ditas inovadoras na vida escolar. No entanto, temas inseparáveis do existir humano, como a sexualidade, e nela a compreensão de corporeidade, permanecem velados no cotidiano das instituições educativas, embora intensamente vividos nos seus currículos ocultos. Mesmo que aparentemente "silenciado" na prática educacional, esse tema transversal da sexualidade vai delineando as relaçóes pessoais e profissionais dos envolvidos no processo curricular sem que se perceba que, numa perspectiva repressora, esse silenciar é muitas vezes um falar enfático. Assim, perpetuam-se muitos conceitos equivocados, mitos, tabus e preconceitos; enfim, vive-se uma constante falta de reflexão intencional sobre o tema e, mesmo que não prevista, essa negligência desumanizadora ocorre na formação inicial e continuada dos/as profissionais das mais diversas áreas do saber, especialmente da Educação e da Saúde.

Analisando Silva (1998) e Yared (2011), pode-se constatar, concretamente, que a escola, em seus vários níveis de ensino, continua sendo, por decisão de seus profissionais, um espaço que constantemente recorre aos seus professores de Ciências e Biologia, preferencialmente, e na sequência, a profissionais externos da área da saúde para ministrarem palestras isoladas de educação sexual para seus estudantes. De acordo com Yared (2011), verificou-se em pesquisa em uma Instituição de Ensino Superior (IES) que as palestras lá desenvolvidas normalmente eram ministradas por profissionais da área da saúde, convidados ou indicados pela própria Secretaria de Educação Municipal. Verificou-se inclusive "parcerias" entre algumas unidades escolares e a Universidade pesquisada para que seus estagiários da área da saúde desenvolvessem trabalhos com os estudantes na escola sobre o tema, com a justificativa de que os professores da instituição não "teriam tempo" para tal. Constatou-se também que essas palestras isoladas podiam ser caracterizadas como intervençôes pontuais, onde prevalecia a transmissão de algumas informaçóes, na maioria dos casos com um enfoque apenas em uma informação biológica restrita, sem que fosse estabelecida nenhuma conexão mais aprofundada com toda a complexidade do existir humano.

Consequentemente, pode-se notar que ainda há traços de um predomínio da concepção higienista da sexualidade nos currículos escolares brasileiros, priorizando com o alunado, nas intervençóes educativas intencionais que eventualmente ocorrem nos espaços escolares, seus aspectos higienista em detrimento de outros aspectos que lhe são próprios por se tratar de uma dimensão humana (OLIVEIRA, L., 2007; YARED, 2011).

Reconhece-se ser a informação científica correta e importante, mas sabese também que apenas a transmissão direta de conhecimentos isolados - como ocorre, por exemplo nas palestras pontuais - não ajuda a promover mudanças no 
comportamento dos sujeitos, pois não trabalha profundamente com as emoções, os sentimentos, visto que normalmente focam suas intervençóes em problemas e em suas consequências funestas, não sensibilizando os jovens para um existir pleno e saudável (SANTOS; BRUNS, 2000; SAWAIA, 2002; YARED, 2011). Destaca-se, especialmente, que os docentes em sua maioria atribuem muita credibilidade a pessoas da área da Saúde, que são preferencialmente convidadas para trabalhar o tema da sexualidade nas escolas, uma vez que esses profissionais "estariam mais preparados do que os/as professores/as" (YARED, 2011, p. 103).

Entretanto, acreditar que esses profissionais convidados têm maior conhecimento sobre esse complexo tema ou que são mais capazes de desenvolver intervençóes em educação sexual vem reforçar uma concepção de poder de informação exposta na obra de Paiva (2000). Nela, a autora fundamenta-se em Parker para ressaltar o poder da informação científica que assegura certa ilusão de maior conhecimento sobre o tema aos profissionais da área da saúde, garantindolhes assim trabalhar com mais credibilidade a temática em espaços públicos; porém, na maioria das vezes, a contribuiçâo ocorre a partir de um viés médicohigienista, muitas vezes embasado em abordagens repressoras da sexualidade.

Ressalta-se que assegurar a confiabilidade do desenvolvimento dessas intervençōes a esses profissionais por serem eles da área da saúde não garante um trabalho em educação sexual dentro de uma perspectiva emancipatória dos sujeitos. De acordo com Santos e Bruns (2000), os profissionais da saúde também podem ser "frutos" de uma "má" formação em sexualidade - que muito provavelmente não se deu nessa perspectiva emancipatória - o que descortina essa grande lacuna em sua formação nessa abordagem. Pode também a realidade estar apontando para o fato de que a educação sexual recebida pela maioria dos/ das profissionais da saúde, inclusive dos médicos e médicas, é aquela que brota de um currículo oculto repressor existente. Ou seja, um currículo que, de forma geral, nega implicitamente os corpos-sexuados dos seres humanos e "contribui sobremaneira para sua domesticação, para seu enquadramento" (MELO, 2004, p. 206).

Em sua análise acerca de profissionais médicos convidados para palestrar nas escolas, Silva (1998) afirma haver entre eles uma consciência coletiva de uma autoridade da classe sobre a família e seus impactos na sociedade, além de se reconhecerem como sujeitos que abordam também assuntos e questóes éticas e morais. Porém, muitos deles também reconhecem não estar preparados para abordar intencionalmente o tema da sexualidade, atribuindo este despreparo à lacuna existente em sua formaçáo. Considerarem também o assunto complexo no universo da própria sociedade contemporânea.

Para uma melhor compreensão desse fenômeno - a aliança entre a medicina e a educação - ou seja, da adesão e aceitação do seu poder legitimado pelo sistema 
educacional - faz-se a seguir um breve resgate histórico objetivando-se auxiliar na compreensão sobre a origem do predomínio desse discurso clínico-biologista na Educação. Mais especificamente, tal discurso permeia propostas de educaçáo sexual nas escolas e o entendimento de como esse tipo de prática atribuída preferencialmente aos médicos tornou-se senso-comum, propagando valores que parecem reforçar uma visão biologista redutora da dimensão da sexualidade humana. Faz-se esse resgate por entender-se que essas são questóes que perduram décadas e ainda hoje influenciam a formaçáo de docentes que atuam na área da Educação e da Saúde e, consequentemente, também na formação de profissionais dessas áreas, especialmente os da área médica.

\section{Reflexões sobre a construção e a legitimação do saber médico e sua influência sobre a sexualidade do brasileiro}

A partir do século XVIII, Portugal começou a apresentar um novo interesse em terras brasileiras devido à descoberta do ouro. Até então, de acordo com Costa (2004), as cidades haviam sido literalmente abandonadas pelos portugueses e a ocupação dos territórios fez-se por meio da iniciativa privada colonial, ou seja, pela família latifundiária senhorial que mantinham interesses políticos e econômicos alinhados aos do reino.

Paralelamente à descoberta do ouro, as cidades envolvidas na sua exportaçáo e comercializaçáo começaram a expandir-se, juntamente com o surgimento de uma elite distinta dos interesses do reino. "Negociantes, homens de letras, militares, funcionários públicos, religiosos e outras camadas sociais começaram a se opor à extorsão econômica [...]", (COSTA, 2004, p. 19). Assim, aumentaram de maneira extraordinária as ocorrências de rebeldia e sabotagem econômica à Portugal.

As tentativas de controle para se reconduzir a população à ordem colonial orientavam-se conforme o entendimento de ordem, de lei, de justiça, de transgressão e de punição da época, ou seja, apresentavam uma lógica repressiva. Dentro da Colônia, duas instituiçóes comandavam a ordem desenvolvendo técnicas eficientes para o controle dos sujeitos: a Igreja, por meio da disciplina corporal exercida pela pedagogia jesuítica e o Militarismo, por meio do serviço militar. Até então ainda não aliado ao Estado, o clero defendia seus próprios interesses e unia-se às famílias contra a metrópole, influenciandoas significativamente no que se tratava de questóes estatais. A Igreja também considerava desnecessário qualquer assistência médica às famílias nativas. As leis da época eram estritamente punitivas, visto que "[...] os governantes procuraram dominar a cidade através da legalidade inscrita nas Ordenaçóes. As infraçóes eram punitivas pela justiça e pela polícia [...]: enforcamento, exílio, açoite, etc.” (COSTA, 2004, p. 20). Todavia, o crescimento populacional e o frágil controle 
do Estado contribuíam para a ascensão de uma desordem urbana e, como o Estado tinha interesses econômicos e militares que se alinhavam aos interesses privados da população, a intervenção no social e a regulação das famílias apresentaram-se como situaçóes emergenciais para o controle político sobre o povo.

Porém, a antiga ordem colonial era resistente à nova ordem disciplinar. Várias particularidades demarcaram esse momento, tais como as características da população, da lei e da política da época. A população brasileira era rotulada pelos europeus, de um modo geral, como um povo mestiço, lascivo e sem nacionalidade; portanto, "gente de pior educação, de um caráter o mais libertino, como são negros, mulatos, cabras, mestiços e outras gentes semelhantes" (COSTA, 2004, p. 25). A ausência de identidade nacional era um fator preponderante, pois um "povo mestiço, sem precedentes de outras nações, fez com que a república fosse inaugurada conjuntamente com um modelo de naçáo híbrido" (OLIVEIRA, L., 2007, p. 12).

A militarização, contudo, apresentava limitaçóes intrínsecas devido ao sistema sócio-econômico infundido pela Colônia. Costa (2004) assinala que na Colônia o poder político era dividido em três poderes: o Estado, as famílias latifundiárias e o clero. Neste sentido, a militarização precisava ser eficiente, mas não gerar resistência ao poder. Foi neste cenário - de fragilidade política, de falta de identificação das instâncias com o Estado e da ineficiência do sistema jurídicopolicial diante do meio urbano - que o Estado nacional precisava resolver "[...] como implantar a mecânica de sujeição militar sem criar soldados nem distribuir armas ou, em outros termos, como levar os indivíduos a compactuarem com a ordem estatal sem os riscos da insurreição armada." (COSTA, 2004, p. 28).

Portanto, no Brasil, esse processo de sujeição foi marcado por esses importantes momentos, inclusive, pela transição do Brasil Colônia para o Brasil República, por exemplo, quando emergiram novas configuraçóes políticas e educacionais e, obviamente, novas questóes ideológicas e morais (OLIVEIRA, M., 2004; OLIVEIRA, L., 2007). Foram estes cenários os responsáveis pela elaboração de novas estratégias de coerção, onde novos agentes "[...] foram aliciados, convertidos, manipulados ou reorientados nos seus mais diversos interesses e formas de agir. Este foi o momento de inserção da medicina higiênica no governo político dos indivíduos." (COSTA, 2004, p. 28). Mais, a passagem do século XIX para o século XX foi quando se presenciou a emergência de um conhecimento médico científico, através do qual se possibilitou a instauração da higiene científica no Brasil (OLIVEIRA, M., 2004; OLIVEIRA, L., 2007).

É nesse espaço que a medicina encontra suporte para se consolidar. Considerando-se que no final do século XVIII e início do século XIX a medicina era tida como um conhecimento "popular", uma técnica "alternativa", seu 
discurso era suscetível a contestação, de veracidade questionável (OLIVEIRA, L., 2007). Historicamente, até a chegada do século XIX, a imagem social do profissional médico era vivenciada com relativo desprestígio e, inclusive, mal remunerados. De uma perspectiva científica mais rigorosa, de acordo com Feyerabend (2010, p. 42), "a medicina antes do século XX tinha fama sem conteúdo e progresso sem substância”, uma vez que a racionalidade do saber médico "pouco se distinguia do conhecimento empírico dos jesuítas, pajés, curandeiros, etc.” (COSTA, 2004, p. 74).

E nesse momento histórico, os meios jurídico-legais apresentavam-se ineficientes no controle da população, bem como na infiltração da intimidade familiar. $\mathrm{O}$ controle da saúde nas cidades também se demonstrava inviável pelos fiscais de justiça e "[...] a justiça não sabia como criar e perenizar mecanismos de prazer que se combinassem aos projetos de mudança, seduzindo as famílias e tornando-as amantes do Estado." (COSTA, 2004, p. 63). Foi nessa conjuntura que a medicina, aliando-se às questóes políticas do Estado, apresentou a higiene como solução, pois

o instrumento adequado ao controle da vida íntima deveria, portanto, ostentar insígnias de poder e saber sobre a moral. [...] A própria família deveria animar a produção de seus fiscais. A operação deveria ser ágil, contínua e pouco onerosa. [...] A assimilação eficaz do corretivo estatal não dependia apenas de seu grau de solubilidade. Além de aceitável ele deveria induzir efeitos gratificantes e duradouros. As famílias deveriam sentir-se recompensadas e não punidas pela intervenção do Estado. A mudança tinha que acenar, antes de mais nada, com promessas de lucro capazes de provocar reaçóes em cadeia, que se estendessem ao longo das geraçóes. (COSTA, 2004, p. 63).

A partir desse conjunto de fatores é que a medicina, então, alcançaria sua independência, "aliando-se ao novo sistema contra a antiga ordem colonial. Este progresso fez-se através da higiene, que incorporou a cidade e a população ao campo do saber médico" (COSTA, 2004, p. 28). As fases de experimentaçóes durante o século XIX e na transição para o século XX garantiram o conhecimento "científico" à medicina, transformando seu discurso popular em discurso hegemônico, na maioria das vezes, inquestionável.

Deste modo, a medicina configurou-se efetivamente e a saúde da população tornou-se uma política de Estado com as famílias como alvo principal visto que "o Estado brasileiro sempre encontrou na família um dos mais fortes obstáculos à sua consolidação" (COSTA, 2004, p. 30). A partir de então, a medicina higiênica insere-se no governo político, com a missão de "reconversão das famílias ao Estado pela higiene" (COSTA, 2004, p. 30-31). Esse objetivo encontrou força naquela premissa do povo brasileiro como um povo mestiço, uma mistura tanto 
biológica como cultural, sem caráter nacional (COSTA 2004; OLIVEIRA, L., 2007), o que o tornava um "alvo fácil de uma série de concepçóes importadas principalmente da Europa, como o eugenismo ${ }^{3}$ e o higienismo" (OLIVEIRA, L., 2007, p. 18).

Todavia, ressaltamos que não negamos nem desvalorizamos os benefícios do progresso científico da higiene aos sujeitos. Esses benefícios são inegáveis. Mas, ressaltamos que é importante notar que "a própria eficiência científica da higiene funcionou como auxiliar na política de transformação dos indivíduos em função das razões do Estado", (COSTA, 2004, p. 32). Diante de um histórico descrédito profissional, é no século XIX que a medicina irá lutar arduamente para inverter esse quadro, "procurando monopolizar o saber e condensar na figura do médico o direito de assistir aos doentes", (COSTA, 2004, p.76). Assim, a higiene apareceu incrivelmente convincente, mesmo destacando que fora incentivada pelo interesse do Estado com vistas à saúde da população.

Concomitantes a todos estes eventos houve uma tentativa de maior controle populacional e de desenvolvimento industrial quando a Família Real mudou-se para o Rio de Janeiro, sendo esse período joanino o marco desse novo processo de regulação e controle. A figura de Dom João VI, a partir de 1808, contribuiu para uma fortificação do poder exercido por Portugal. Porém, a chegada da Corte ressaltou as deficiências urbanas da cidade, como os problemas demográficos e o ritmo econômico imposto ao Brasil baseado no capitalismo europeu. A aristocracia portuguesa e a burguesia europeia possuíam costumes - consumo, lazer, moradia, higiene - muitos distintos da populaçáo local, o que os deixava insatisfeitos com o funcionamento da cidade. Havia, portanto, uma necessidade urgente de desenvolvimento urbano e a transformação e higienização das famílias teve ligação direta com essa modernização.

Consequentemente, as relaçôes familiares começaram a ser "atacadas" por propagandas nacionalistas, ação gerenciada por políticos e intensamente apoiada pelos "novos agentes de domesticação familiar, os médicos" (COSTA, 2004, p. 62). As intervençóes da concepção higienista no Brasil durante o século XIX focaram-se no processo de construçáo da autoridade e da confiabilidade e na

3 Eugenia - palavra derivada do grego que significa "bem nascido"; teoria que busca produzir uma seleção nas coletividades humanas baseada em leis genéticas; a concepção eugênica estabelece princípios e regras para a formação de um povo saudável, de uma prole sadia de corpo e espírito, gerando seres humanos com "bons genes”. (HOUAISS, 2009; OLIVEIRA, M., 2004; OLIVEIRA, L., 2007).

4 Higienismo - parte da medicina que visa à preservação da saúde e ao estabelecimento das normas, condutas e preceitos para prevenir as doenças; conjunto de condiçóes ou hábitos que conduzem ao bem-estar e à saúde (HOUAISS, 2009). 
persuasão da hipótese de que "a saúde e a prosperidade da família dependem de sua sujeição ao Estado" (COSTA, 2004, p. 63).

Tais concepçóes instauraram-se no Brasil quando se iniciou a formação científica da medicina propondo novas concepçóes de corpo como foco de ajuste e controle para o aprimoramento e a saúde do povo. Nesse momento, portanto, começaram a entrar em cena os médicos formados neste novo quadro científico - os novos atores sociais que "efetivaram a representação da sexualidade sustentada em doutrinas higienistas e eugenistas" (OLIVEIRA, L., 2007, p. 16). As influências dessas doutrinas refletiam numa "fascinação" pelo corpo burguês, numa contínua avaliação pejorativa do corpo, banalizando os sujeitos suprimidos da elite socioeconômica, como por exemplo, os paraíbas, os crioulos ou os caipiras.

Pode-se constatar, assim, que esses conhecimentos e pensamentos geravam uma "desqualificação" do povo brasileiro. Segundo Morin (2007, p. 98), "[...] é o modo de pensar dominante, redutor e simplificador, aliado aos mecanismos de incompreensão, que determina a redução da personalidade, múltipla por natureza, a um único de seus traços." A higiene e a disciplina passaram a ser categorias marcantes na distinção social; porém, a "[...] possessão por uma ideia, uma fé, que dá a convicção absoluta de sua verdade, aniquila qualquer possibilidade de compreensão de outra ideia, de outra fé, de outra pessoa." (MORIN, 2007, p.98). E assim, consequentemente,

[...] o corpo, o sexo e os sentimentos conjugais, parentais e filiais passaram a ser programadamente usados como instrumentos de dominação política e sinais de diferenciação social daquela classe. [...] A ética que ordena o convívio social burguês modelou o convívio familiar, reproduzindo, no interior das casas, os conflitos e antagonismos de classe existentes na sociedade. As relaçôes intrafamiliares se tornaram uma réplica das relaçôes entre classes sociais. (COSTA, 2004, p. 13).

Logo, esses critérios marcavam uma nova sociedade moderna a partir do século XX, onde a sexualidade representava uma política de controle dos sujeitos e da população. Esse "controle sobre as pessoas e as coisas", relacionado ao pensamento do governo no período joanino, vem ao encontro do pensamento abissal firmado por Santos (2010), que apresenta uma lógica de "apropriaçáo/ violência" estabelecida quando ocorrem situaçóes muito desiguais de poder: "mais do que regular os conflitos sociais entre cidadãos, é solicitado a suprimir conflitos sociais" (SANTOS, 2010, p. 48). O modo sistemático e calculado como o corpo, o sexo e as relaçôes intrafamiliares são utilizados para normalizar as condutas fundamentadas na ordem social burguesa europeia representa o poder e a manipulação exercidos pelo governo sobre a população. 
A forma de poder é simples e bastante popular. Não há qualquer argumento: não há qualquer tentativa de entender; a forma de vida que tem o poder impóe sua regra e elimina o comportamento que lhe é contrário. Conquistas estrangeiras, a colonização, os programas de desenvolvimento e uma grande parte da educação ocidental são exemplos disso. (FEYERABEND, 2010, p.34).

Portanto, o poder, o controle e a regulação da população pelo Estado fortaleceram-se a partir da intervenção médica orquestrada pelo discurso higienista - açóes que influenciam muitas das condutas humanas até os dias atuais.

\section{Indicadores dos reflexos do legado higienista e eugenista europeu nos ambientes escolares brasileiros}

A marcha higienista teve origem na Europa e seu nome se origina na raiz grega hygies, que significa sadio. Indubitavelmente necessária, a higiene preocupase com o ambiente e com a saúde do ser humano, ensinando-o como protegê-la e melhorá-la, além do cuidado com o "favorecimento e ótimo funcionamento do organismo, ajustando-o ao meio, cuidando de impedir e combater doenças" (OLIVEIRA, M., 2004, p. 01). No entanto, a característica "mestiça” do povo brasileiro era vista como uma fragilidade e, assim, o movimento higienista europeu instaurou a tentativa de uniformizar e padronizar esse povo. $\mathrm{O}$ reflexo dessa ação foi o acesso da medicina ao núcleo familiar, pois os médicos dominavam esse novo saber científico e desenvolviam "dispositivos estratégicos de regulação dos comportamentos e da vida íntima dos diversos setores da sociedade" (OLIVEIRA, L., 2007, p. 27).

A inserção do médico e, consequentemente, da medicina higiênica no governo político objetivou compensar as deficiências da lei, originando uma política higiênica que cultivasse "o gosto pela saúde, exterminando assim, a desordem higiênica dos velhos hábitos coloniais" (COSTA, 2004, p. 12), salvando a população do caos em que se encontravam. Ou seja, a inclusão desses dispositivos médicos era apregoada como importante para garantir a transformação dos sujeitos em cidadãos metropolitanos. $\mathrm{O}$ modo de conviver burguês, implicitamente "é transmitido [...] onde o ideal do gentleman, do petit bourgeois contido, disciplinado, higiênico e polido, funciona como norma do bem conduzir-se na casa e na vida”, (COSTA, 2004, p. 88).

A tarefa dos higienistas era a de converter os sujeitos à nova ordem urbana. Ordem estranha ao antigo modo de viver colonial que, a todo momento, a repelia e procurava deter seu progresso. Esta ordem, contudo, precisava ser aceita, pois dela dependia a prosperidade das elites e o progresso do Estado. 
A ingerência médica na família perseguia este objetivo: tornar o estranho, familiar. (COSTA, 2004, p. 35-36).

Logo, tendo como foco o controle e regulação das famílias brasileiras, o higienismo e o eugenismo preconizam o ensino de novos hábitos, enraizandose em setores como a Saúde Pública e a Educação. A repercussão desses conhecimentos era inicialmente empírica até o século XVIII; porém, a partir do século XIX, experimentos concretizaram a propagação da higiene científica (OLIVEIRA, M., 2004). No âmbito da saúde o poder público iniciava o planejamento e a adoção de campanhas educativas, o "policiamento sanitário, saneamento de portos e cidades, imunização em massa e isolamento de doentes" (OLIVEIRA, L., 2007, p.19). No âmbito privado, o ações médicas mas sempre entendidas como açóes políticas - organizavam a "gestão estatal dos casamentos, nascimentos e sobrevivências" pois o "sexo e sua fecundidade precisavam ser administrados. A medicina das perversóes e os programas de eugenia foram, na tecnologia do sexo, as duas grandes inovaçóes da segunda metade do século XIX”, (FOUCAULT, 2011, p. 129). Açôes estas que se caracterizavam como nada menos do que um sistema de regulação que, aliadas ao eugenismo e ao higienismo, trabalhavam como ciência para remodelar o povo brasileiro.

A concepção higienista defende a formação de um sujeito puramente burguês e à disposição das políticas do Estado. Portanto, o foco da medicina social será as famílias burguesas da cidade, "[...] procurando modificar a conduta física, intelectual, moral, sexual e social dos seus membros com vistas à sua adaptação ao sistema econômico e político." (COSTA, 2004, p. 33). Isso não significa que o Estado não tivesse interesse no controle da outra parte da população; ao contrário, não tinha interesse em modificar seus padróes familiares, mas sim em manter sua represália e obediência ao código punitivo. Inclusive, seriam colocados como exemplos de desvio da "normalidade" higiênica científica. Dessa forma, os "[...] escravos, mendigos, loucos, vagabundos, ciganos, capoeiras, etc., servirão de anti-norma, de casoslimite de infração higiênica. A eles vão ser dedicadas outras políticas médicas [...]" (COSTA, 2004, p. 33). Políticas essas decididas e sempre implantadas pelos governantes, mostrando a manutenção e reproduçáo do poder do Estado sobre o povo, pois eram decisôes quase nunca tomadas em conjunto com a população (FEYERABEND, 2010).

Por meio da Educaçáo Sexual, o higienismo e eugenismo transformavam homens e mulheres em seres apenas reprodutivos e guardióes das futuras proles, que deveriam ser sấs e de "raças puras". Consequentemente, reduziram os relacionamentos sexuais a condutas sociais e sentimentais apenas de pai e mãe. Por isso, essa educação 
[...] desencadeou uma epidemia de repressão sexual intrafamiliar que, até bem pouco tempo, transformou a casa burguesa numa verdadeira filial da "polícia médica". Instigados pela higiene, homens passaram a oprimir mulheres com o machismo; mulheres, a tiranizar homens com o "nervosismo"; adultos, a brutalizar crianças que se masturbavam; casados, a humilhar solteiros que não casavam; heterossexuais, a reprimir homossexuais, etc. $\mathrm{O}$ sexo tornou-se emblema de respeito e poder sociais. Os indivíduos passaram a usá-lo como arma de prestígio, vingança e punição. (COSTA, 2004, p. 15, grifo do autor).

Desta maneira, a medicina insere-se entáo no interior das famílias burguesas, com vistas à saúde e educação das crianças; defendendo seu controle e sua saúde física e moral. Para o controle e regulação das famílias mais pobres, elaboravamse campanhas de moralização e higiene. Logo, implantava-se, assim, um sentimento de solidariedade pelas elites, pela filantropia, com vistas à repressão dos cidadãos discordantes, garantindo até hoje o que seria o bom funcionamento das políticas de Estado.

Firmada pelo discurso clínico, a medicina detém um "domínio epistemológico" (FOUCAULT, 2008) sobre os sujeitos e por meio da concepção higienista promove a normalização de condutas aceitáveis e não aceitáveis sobre a vida íntima das famílias brasileiras. Condutas classificadas perante o poder e a regulação do discurso clínico e caracterizadas como "normal" e "anormal". Silva (1998) também ancora sua pesquisa nas consideraçóes de Foucault a respeito da ciência como um artifício de poder, visto que relaciona o saber médico em sexualidade com o poder de classificar e enquadras padróes de normalidade e anormalidade. Reconhece-se, então, que a medicina clínica pode ser caracterizada tanto como um "[...] conjunto de prescrições políticas, decisóes econômicas, regulamentos institucionais, modelos de ensino quanto um conjunto de descrições [...]" (FOUCAULT, 2008, p. 100).

Com o objetivo de instaurar regras e modelos para a população, o grande alvo das campanhas médicas e governamentais passou a ser as chamadas "doenças sociais" - tuberculose, febre amarela, lepra e sífilis - reduzindo os seres humanos às doenças que apresentam. Esse momento foi tâo marcante na história brasileira que tais campanhas eram elaboradas com vistas ao "melhoramento" da nossa raça e para o desenvolvimento da nação. Devido à representação produzida pelo eugenismo, vê-se no povo brasileiro um povo preguiçoso, indolente, improdutivo e que estava doente por ter sido abandonado pelas elites políticas, justificando, assim, o atraso do país em relação aos EUA e à Europa. Nesse ponto, a medicina científica entra em cena, alegando que a causa da nossa inferioridade e improdutividade era a mestiçagem e o clima tropical do Brasil. Dessa forma, para salvar o nosso país, seria necessário higienizá-lo, saneá-lo, melhorá-lo, lutar 
contra a não uniformidade, visto que a doença era vista como o maior obstáculo para se chegar à civilização (OLIVEIRA, L., 2007).

Dentre essas "doenças sociais", a sífilis foi a que despertou maior atenção. Considerada uma das maiores epidemias da virada do século XIX para o século $\mathrm{XX}$, a sífilis encontrava-se no topo de interesse do discurso médico, pois, ao se descobrir que seu contágio era predominantemente sexual, essa doença demarcava a moralidade do cidadão. Ressalta-se que nesse momento do cenário brasileiro, juntamente com o discurso clínico estava presente também o catolicismo, uma crença dominante (e o é até os dias atuais) que ditava o modo de vida dos cidadãos. As pessoas sifilíticas eram caracterizadas como "[...] homens e mulheres de vícios, promíscuos e libertinos, eram os alvos principais da intervenção ao mesmo tempo moral, divina, educacional e médica [...]" (OLIVEIRA, L., 2007, p. 39). Assim, juntamente com a medicina e o catolicismo, o Estado reforçava o seu poder enquanto médicos explicitavam os problemas relacionados à vida sexual - especialmente ligados à sífilis - e aconselhavam a população a adotar um estilo de vida equivalente ao proposto pelo catolicismo.

Consequentemente, a representação da sexualidade apresentou-se como de competência médica-higiênica, pois era um tema "diretamente vinculado aos preceitos higienistas, eugênicos, morais, médicos e educacionais da época" (OLIVEIRA, L., 2007, p.26). Assim, por meio do discurso médico e da "medicinalização do insólito sexual" (FOUCAULT, 2011, p.52) almejava-se, uma "sexualidade sadia", a qual deveria instaurar-se como norma de conduta entre os brasileiros, com apoio do saber médico, que seria então legitimado por meio da propagação de suas ideias, costumes e valores na educação formal e não formal. É deste modo, como agentes de regulação do cotidiano, controlando a saúde da população brasileira - homens, mulheres e crianças -, que os médicos "[...] passam a ditar as normas de existência, reprodução, movimentação social, aprimoramento da espécie e desenvolvimento de potencialidades [...]" (OLIVEIRA, L., 2007, p. 31-32).

Emergia assim, um "novo povo, uma nova sociedade", que seria formada nas escolas. A higiene estabeleceu padróes na formação de um corpo sadio e de uma consciência nacionalista, visto que os médicos também "[...] perceberam que a escola não poderia ser mais o cenário para a reprodução dos padróes valorativos e educacionais familiares, nem táo pouco da desordem que caracterizava a organização doméstica." (OLIVEIRA, L., 2007, p. 25). Todo o espaço escolar começa a ser elaborado a partir da sexualidade das crianças, como por exemplo, as salas de aula, as formas das mesas, a organização dos dormitórios, a vigilância, o horário de recolhimento, etc. Segundo Foucault (2011), sexualidade das crianças e dos adolescentes - vista como precoce, ativa, permanente - passa a ser entendida como um problema público, pois 
[...] os médicos se dirigem aos diretores dos estabelecimentos e aos professores, também dáo conselhos às famílias, os pedagogos fazem projetos e os submetem às autoridades; os professores se voltam para os alunos [...] cheios de conselhos médicos e de exemplos edificantes. Toda uma literatura de preceitos, pareceres, observaçôes, advertências médicas, casos clínicos, esquemas de reforma e planos de instituiçóes ideais, prolifera em torno do colegial e de seu sexo. (FOUCAULT, 2011, p. 34 e 35).

Neste sentido, a partir do processo de organização social e da imposição de novos hábitos e valores, além das campanhas de saúde e criação de políticas públicas, se visava também na "educação escolar um meio de higienização da população", (OLIVEIRA, M., 2004, p. 09) Todavia, comparava-se a educação escolar brasileira com a europeia e essas concepçóes alimentavam no Brasil uma sensação de inferioridade quanto às práticas educacionais científicas realizadas.

Portanto, a aliança entre a medicina e a educação se deu pela apropriação do discurso médico no período da Primeira República 5 , pois “aos médicos era atribuída a prerrogativa de alicerçar as bases sobre as quais toda uma nação poderia ser gerenciada" (OLIVEIRA, L., 2007, p. 37) - o que originou a percepçáo de uma medicina salvadora que ajudaria a produzir uma naçáo saudável e curável.

Esse poder só se legitimou a partir do momento que se introduziu no cotidiano do povo a compreensão de cura como redenção. Todavia, "para alguém ser curado, é preciso estar convencido de que está doente e de que existe um agente habilitado a promover a cura" (OLIVEIRA, L., 2007, p. 38). Assim, o convencimento da doença originava-se pelo médico a partir de uma moral estabelecida nas mentalidades da época. Contudo, cabe ressaltar que a autoridade dos médicos não adveio somente dos discursos apresentados à população, mas também da eficácia nas ações guiadas pela medicina, como abordadas anteriormente, as quais, certamente, não podem ser subestimadas.

Pode-se justificar, assim, a adesão e aceitação do sistema educacional à concepção higienista, às novas práticas e orientações de saúde que eram (e são) hegemonicamente dominadas e controladas pelo discurso médico, presente nos currículos escolares direcionados para a formação de professores a partir da década de 1920 (OLIVEIRA, M., 2004).

Essas prescriçôes higienistas e eugenistas contribuíram para que a classe médica fosse considerada não somente uma elite intelectual, "mas principalmente pragmática responsável por ditar regras de comportamento" (OLIVEIRA, L.,

5 Período da história do Brasil registrado da Proclamação da República em 15 de novembro de 1889 até a Revolução de 1930 quando inicia-se o governo de Getúlio Vargas. 
2007, p. 32). Também cabe ressaltar que a partir do século XVIII, com a gradual legitimação de seu discurso, o médico foi substituindo o curandeiro e, no Brasil República, como resultado das influências europeias, esse agente social promoveu diversas açóes eficazes e efetivas no tratamento e profilaxia das mais variadas doenças. Por isso, os médicos ganharam "[...] autoridade para se apresentarem como os agentes portadores das melhores práticas sociais, legitimando-se como condutores do povo, particularmente no que se refere à vida íntima e à vida sexual." (OLIVEIRA, L., 2007, p. 32).

Portanto, instaurou-se na Primeira República, e perpetua-se até os dias atuais, o interesse de uma aliança entre médicos e educadores, elo que talvez explique a reproduçáo de muitas dessas concepçóes de sexualidade estarem atualmente presentes na sociedade em geral e, particularmente, nas escolas, inclusive nas escolas formadoras de médicos, ou seja, nos cursos de medicina brasileiros.

\section{Reflexões sobre a herança do legado higienista e eugenista europeu, o discurso médico e algumas das suas possíveis implicações na educação brasileira}

A partir desta retrospectiva histórica, entendemos ser urgente e necessária a análise da compreensão de docentes dos cursos de medicina acerca da dimensão da sexualidade humana e como estes percebem a sexualidade vivenciada ao longo de sua prática pedagógica. Ao revelar a compreensão desses profissionais sobre a temática poderemos obter respostas para a pergunta fundamental: Quem é e como foi formado o formador de médicos no que se refere à Educação Sexual?

$\mathrm{Na}$ releitura das análises na Dissertação de Yared (2011), percebe-se que esta corrobora muitos dos achados de Silva (1998), que também identificou essa demanda da escola e profissionais da Educação pelos profissionais da Saúde. Também averiguou Yared (2011) a inexistência de um trabalho intencional sistemático sobre sexualidade na formação inicial e continuada dos professores e que devido a essa lacuna tais profissionais apresentam medo e insegurança para abordar o tema, além de acreditarem, como descrito anteriormente, que não passam credibilidade aos estudantes. Justificam, assim, a busca constante por profissionais "mais preparados" para executarem essas intervenções.

E como, então, são formados esses profissionais da saúde que seriam os especialistas procurados pelos profissionais da educação para tratar de sexualidade nas escolas? Entendemos ser relevante a realização de vários outros estudos intencionais que levem à ampliação de nossa compreensão das abordagens existentes sobre o tema da sexualidade humana na formação médica. Abordagens expressas nos currículos de seus cursos, entendidas como escolhas pedagógicas não neutras, pois são construídas e propostas por 
pessoas com valores e ideologias e transformadas cotidianamente em práticas pedagógicas pelos docentes que lá atuam.

E como compreendem estes docentes essa questáo? Sabemos do poder social singular dessa profissão na sociedade contemporânea, mas há que se resgatar que médicos são também pessoas sempre sexuadas, assim como seus docentes dos cursos que os formam, para os quais a construção da sexualidade também ocorre ao longo da vida, de muitas formas influenciando seu modo de pensar, sentir e agir. Portanto, possuem características singulares que se constroem e são construtoras de saberes e práticas tanto individuais quanto coletivas. Cada indivíduo atravessa os diferentes períodos da vida trazendo consigo imagens, recordaçóes e valores da convivência escolar, social e familiar, as quais proporcionaram sua construção de ser humano e influenciam na sua interaçáo com o mundo. Assim, "[...] a sexualidade é um universo que precisa ser entendido como um conjunto de atividades, posturas, opçóes, modos de vida, subjetividade e alteridade, resultantes das relaçôes sociais." (SILVA, 1998, p. 120).

Esses docentes têm clareza dessas questôes? Há em sua prática pedagógica o debate e o entendimento sobre a remodelação do povo brasileiro por meio da padronizaçáo de comportamento e condutas, do controle e regulação das famílias, da imposição de hábitos e valores, com vistas a uma "sexualidade sadia"? A importância da higiene é inquestionável, mas esses professores de futuros médicos e médicas compreendem a relação do higienismo aliado ao eugenismo, na manutenção e reprodução do poder e controle estatal? Esses futuros profissionais formados terão esclarecimento sobre o "domínio epistemológico" e a legitimidade de seu papel social, para serem capazes de ressignificar esse discurso do saber médico junto à população brasileira, especialmente nos espaços escolares, inclusive em cursos de medicina? São perguntas que podem ser respondidas com estudos intencionais que desvelem esta compreensão sobre o tema.

Mesmo para os médicos - por força de sua formação, portadores de um saber científico que pressupóe um vasto conhecimento biológico -, há que se relembrar que a sexualidade encontra-se na base das expressóes humanas. É constituinte e constituída nas relações da condição humana, visto que não é uma simples expressão biológica, pois os seres humanos tem a consciência do prazer e do desejo intencional, transformando-a em atividade erótica e sensual. Nesta perspectiva, pode-se afirmar que o ser humano não 'tem' sexualidade, ele 'é' sexualidade, como podemos encontrar exposto com sensibilidade nas obras de Cabral (1995) e Silva (1998).

Reiteramos, então, que essa sexualidade humana oculta ou desvelada nos currículos de formação médica vivenciada por seus docentes e discentes também não está isenta de mitos, tabus, preconceitos, construçôes e significaçôes de 
modelos históricos e sociais, nem de possíveis abordagens pedagógicas pautadas num paradigma repressor da sexualidade, pois não se desassociam do corpo, ela é o próprio corpo. "O corpo é a sede tanto da sexualidade como do trabalho e de qualquer outra atividade humana" (MELO, 2004, p. 49) e, segundo Silva (1998), como o corpo é apropriado pela cultura e base de representaçóes sociais, a sexualidade está repleta de significaçóes sociais, culturais e políticas que expressam a história individual dos sujeitos. Mas se os médicos tratarem do corpo apenas como marca biológica porque o currículo acadêmico assim os construiu como profissionais, todas essas significaçôes serão desconsideradas, com sérias consequências para a desumanização da medicina. Se as propostas curriculares da formação médica e os saberes e fazeres pedagógicos que daí resultarem dos seus docentes tratarem do corpo com abordagens que reforçam sua domesticação, seu controle e sua negação, os profissionais egressos desses cursos tenderão a reproduzir esse modelo.

Há que se reafirmar, como Queiroz (2000), que o corpo é concebido socialmente, adestrado pela cultura e transformado por crenças e ideais coletivos. Melo (2004) mostra grande preocupação com essa "descorporificaçáo" dos seres humanos, visto que ao longo da história e do processo de construção sócio-histórico-cultural dos sujeitos, a percepção redutora de corpo advém das experiências e das relaçóes com a família e com os sistemas educativos, sem que se possa também ignorar a influência da religião na cultura ocidental.

Percorrendo com Melo (2004) os caminhos da Idade Clássica e Medieval e a inegável influência do cristianismo, tem-se que a imagem de corpo ao longo da história resultou numa visão dual do ser humano, uma visão fragmentada de corpo e mente, uma visão dicotômica de corpo e alma, que levou a esse "processo de ocultamente do corpo, de sua depreciação e negação" (MELO 2004, p. 43). E é esse processo de negação que parece atravessar ainda hoje a prática pedagógica de alguns currículos de cursos de medicina. Será possível sua superação?

Vamos, então, à Merleau-Ponty (1999) citado por Melo (2004): esse autor nega qualquer dicotomia corpo-mente nos seres humanos, uma vez que "o homem é corpo-alma em indissolúvel unidade, em que o corpo é seu modo de Ser no mundo", (MERLEU-PONTY 1999 apud MELO, 2004, p. 42). Ou seja, não estamos no corpo, nós somos o corpo. Dessa forma, considera-se o corpo como um veículo de ação e interação do Ser humano no mundo, pois passamos a utilizar a categoria plena da corporeidade e náo mais apenas corpo, pois esta "[...] implica na inserção de um corpo humano em um mundo significativo, a relação dialética do corpo consigo mesmo, com outros corpos expressivos e com os objetos de seu mundo." (OLIVIER 1998 apud MELO, 2004, p. 89).

E na corporeidade, a sexualidade, aqui compreendida como uma dimensão humana, não é externa ao sujeito, de suas ações, pensamentos e comportamentos 
e "não pode ser reduzida como um objeto estranho fora de nós" (NUNES, 2005, p. 19). A sexualidade náo é nem transcendida na vida humana, nem figurada em seu centro por representaçóes inconscientes. "Ela está constantemente presente ali, como uma atmosfera. [...] A sexualidade é coextensiva à vida." (MERLEAUPONTY, 1999, p. 232-233). Logo, o ser humano 'corpo no mundo' não pode apresentar sua sexualidade como algo isolado, algo "deixado de fora", inclusive, do ambiente escolar, aí incluída a questão da formação médica. "Os corpos são as pessoas, pessoas estas sempre sexuadas" (MELO, 2004, p. 52).

Assim, adota-se acriticamente ainda hoje, em muitas das expressóes do existir humano, um padrão hegemônico de vivência da sexualidade, reduzindo esse existir, por exemplo, apenas ao matrimônio monogâmico na adultez heterossexual com fins reprodutivos. E, assim, tantas outras abordagens redutoras de um viver pleno das pessoas, aí incluída, já que delas é inseparável, a dimensão da sexualidade. Todos esses saberes e fazeres, esses discursos "verdadeiros" produzidos sobre o sexo são absorvidos inteiramente, por exemplo, pela família conjugal, num processo considerado legítimo de "apenas para reprodução". Por um lado, transformam o sexo em algo negado, reduzido ao silêncio, reservando-o ao princípio de um segredo e por outro, criam novos discursos de poderes, estabelecendo novas dominaçôes de uns sobre outros. Consequentemente, amplia-se o poder, ou seja, multiplica-se as correlaçóes de forças inerentes ao domínio. De acordo com Foucault (2011, p.103), o poder está em todas as partes, sendo uma "situação estratégica complexa numa sociedade determinada" e, assim,

[...] o discurso veicula e produz poder; reforça-o mas também o mina, expóe, debilita e permite barrá-lo. Da mesma forma, o silêncio e o segredo dão guarida ao poder, fixam suas interdições; mas, também, afrouxam seus laços e dão margem a tolerâncias mais ou menos obscuras. (FOUCAULT, 2011, p.112).

Entendendo que a construção de uma abordagem emancipatória de educação deve ser continuada e permanente, um trabalho de Educação Sexual intencional que aborde a sexualidade como dimensão inseparável do existir humano pode e deve ter um entendimento para além do sexo restrito, não se limitando, portanto, a um momento único e exclusivo no fluxo da existência social. As palestras, que até podem ser realizadas por médicos, também podem vir a ser instrumentos positivos de intervençôes quando utilizadas na complementação de um trabalho intencional, sistemático de Educação Sexual, planejado coletivamente pela comunidade que o recebe. Um trabalho entendido como um processo permanente, parte da vida e não apenas como uma ocasional metodologia, uma vez que deve envolver também questôes referentes a “[...] 
sentimentos, valores, atitudes e normas socioculturais ligadas à sexualidade, construídas e transformadas pelo homem ao longo da história." (FIGUEIRÓ, 2006, p. 262).

\section{Considerações finais}

Nesse ponto das nossas reflexóes, percebemos que dentre as várias vertentes pedagógicas sobre sexualidade na formação médica, a concepção médicohigienista, num sentido redutor, apresenta-se ainda como forte norteador de muitas das ações em Saúde Pública, como resultado da preponderância dessa abordagem nos currículos dos cursos de medicina. Esses saberes e essas práticas médicas fortalecem, portanto, a perpetuação de um modelo de sexualidade dito "normal", visto que muitas das práticas fora da heteronormatividade, por exemplo, ainda são consideradas por muitos como patológicas. Nessa direção, relembramos o que afirma Foucault (2011): após a medicalização da confissão, o domínio do sexo não é mais exclusivo da "culpa e do pecado", mas do "normal e do patológico" e, a partir dessa ótica, "[...] a sexualidade foi definida como sendo, por natureza, um domínio penetrável por processos patológicos, solicitando, portanto, intervençôes terapêuticas ou de normalização." (FOUCAULT, 2011, p. 77-78, grifo do autor).

Consequentemente, a carência desses referenciais humanistas específicos sobre sexualidade e educação sexual na prática pedagógica de docentes de cursos de medicina causa inquietaçôes, visto que a educação sexual está sempre ocorrendo em seu currículo oculto e até abordagem intencional daí decorrente que possa surgir pode ser desenvolvida sem o compromisso com uma abordagem crítica e emancipadora, sem o planejamento coletivo e a competência necessária. Esta é uma realidade possível, já que a formação médica ainda carrega uma herança filosófica de, muitas vezes, tratar apenas das 'anormalidades' e/ou perversôes na questão específica de manifestaçôes da sexualidade. Pois como aponta Louro (2000, p.41-42, grifo da autora), "[...] uma infinidade de teorias médicas, psicológicas e religiosas é acionada para reconduzir essas mulheres e esses homens à posição correta e sadia - a heterossexualidade."

Mas quem educa "sexualmente" hoje esses futuros médicos? Essas reflexôes buscam ajudar na sensibilização de todos os envolvidos, docentes médicos e docentes náo médicos de cursos de medicina, em processos de formação de profissionais médicos, sobre a viabilidade de um trabalho de educação sexual emancipatório, aí incluída também a formação de quem forma o profissional da medicina, para auxiliar o sujeito no autoconhecimento e na reflexão sobre sua própria sexualidade. Dessa forma se estará favorecendo a vivência de uma sexualidade que valoriza o prazer, a diversidade, o respeito 
mútuo, na busca da saúde sexual trabalhada como proposta na Declaração dos Direitos Sexuais: como Direitos Humanos, entendido como fundamentais e universais. (WAS, 2014).

Ressalta-se que o profissional médico ocupa uma função social de quem tem um saber autorizado sobre sexualidade, o que, de acordo com Silva (1998), é ainda uma expressáo legal de poder e dominação institucional. Levantamos, então, a hipótese de que desse espaço legal e institucional o profissional médico, se formado numa perspectiva emancipadora do sujeito, pode ser responsável por trabalhos emancipatórios em sexualidade na área da Saúde e na Educação, podendo contribuir com muita propriedade, pela função social que ocupa, para o desenvolvimento de novas ideias e novas opinióes embasadas na ética em torno da dimensão humana da sexualidade.

Por fim, as reflexôes até aqui compartilhadas, almejam que estes currículos formem profissionais de medicina mais sensibilizados para uma compreensão crítica dessa temática. Conforme já explicitados, esses profissionais, auxiliados pelos docentes de seus cursos nessa perspectiva emancipadora, com seus currículos ressignificados, podem ressignificar também sua própria sexualidade, colaborando para a construção de conhecimentos científicos que sejam entendidos como fruto da construção sócio-histórico-cultural humana, construção esta sempre sexuada. Nesse processo, o entendimento de sexualidade teria sim implicações biológicas, mas também filosóficas, antropológicas, históricas, sociais e políticas na vida de cada sujeito, reiteramos, aí incluídos os profissionais da medicina e os docentes que ajudam a formá-los, todos entendidos como seres sexuados que vivenciarão em plenitude o que registra Merleau-Ponty (1999, p.207-208): "eu não estou diante do meu corpo, estou em meu corpo, ou antes, sou meu corpo."

\section{REFERÊNCIAS}

CABRAL, J. T. A sexualidade no mundo ocidental. Campinas: Papirus, 1995.

COSTA, J. F. Ordem médica e norma familiar. Rio de janeiro: Graal, 2004.

FEYERABEND, P. K. Adeus à razáo. Tradução de Vera Joscelyne. São Paulo: Ed. da UNESP, 2010.

FIGUEIRÓ, M. N. D. Formação de educadores sexuais: adiar não é mais possível. Campinas, SP: Mercado das Letras ; Londrina: EDUEL, 2006.

FOUCAULT, M. História da sexualidade I: a vontade de saber. Tradução de Maria Thereza da Costa Albuquerque e José Augusto Guilhon Albuquerque. Rio de Janeiro: Graal, 2011.

Arqueologia das ciências e história dos sistemas de pensamento. Organização e seleção de textos de Manoel Barros da Motta. Tradução de Elisa Monteiro. 2.ed. Rio de Janeiro: Forense Universitária, 2008. 
HOUAISS, A. Dicionário eletrônico Houaiss da língua portuguesa. Rio de Janeiro: Objetiva, 2009.

LOURO, G. L. Currículo, género e sexualidade. Porto: Porto Editora, 2000.

MELO, S. M. M. de. Corpos no espelho: a percepção da corporeidade em professoras. Campinas, SP: Mercado de Letras, 2004. (Coleção Dimensóes da Sexualidade).

MELO, S. M. M. de.; POCOVI, R. Educação e sexualidade. 2. ed. Florianópolis: UDESC, 2008. [Caderno Pedagógico, v.1].

MERLEAU-PONTY, M. Fenomenologia da percepção. São Paulo: Martins Fontes, 1999.

MORIN, E. Os sete saberes necessários à educaçáo do futuro. Traduçáo de Catarina Eleonora Ferreira da Silva e Jeanne Sawaya. Revisão técnica de Edgard de Assis Carvalho. 12.ed. São Paulo: Cortez ; Brasília: UNESCO, 2007.

NUNES, C.A. Desvendando a sexualidade. 7.ed. Campinas, SP: Papirus, 2005.

OLIVEIRA, L. S. Representação de sexualidade que orienta práticas educativas no Brasil desde o final do século XIX. 2007. 81f. Dissertação (Mestrado em Educação e Cultura Contemporânea) - Universidade Estácio de Sá, Rio de Janeiro, 2007.

OLIVEIRA, M. T. Prescriçóes médicas sobre higiene e sexualidade e suas relaçóes com a educaçáo: 1920-1930. 2004. 129f. Dissertação (Mestrado em Educação) - Universidade Federal do Paraná, Curitiba, 2004.

PAIVA, V. Fazendo arte com camisinha. São Paulo: Summus, 2000.

QUEIROZ, R. da S. (Org.). O corpo do brasileiro: estudos de estética e beleza. São Paulo: Senac, 2000.

SANTOS, B. de S. Para além do pensamento abissal: das linhas globais a uma ecologia de saberes. In: SANTOS, B. de S.; MENESES, M. P. (Org.). Epistemologias do Sul. São Paulo: Cortez, 2010. p.23-71.

SANTOS, C.; BRUNS, M. A. de T. A educação sexual pede espaço: novos horizontes para a práxis pedagógica. São Paulo: Ômega, 2000.

SAWAIA, B. B. O sofrimento ético-político como categoria de análise da dialética exclusão/ inclusão. In: SAWAIA, B. B. (Org.). As artimanhas da exclusáo: análise psicossocial e ética da desigualdade social. 4. ed. Petrópolis: Vozes, 2002. p.07-15.

SILVA, E. A escola, a clínica e a sexualidade humana. Revista Perspectiva, Florianópolis, v.16, n. 30, p.115-142, jul./dez. 1998.

WORLD ASSOCIATION FOR SEXUAL HEALTH [WAS]. Declaraçáo dos direitos sexuais. 2014. Disponível em: <http://www.worldsexology.org/wp-content/ uploads/2013/08/DSR-Portugese.pdf>. Acesso em: 2 set. 2015.

YARED, Y. B. A educaçáo sexual na escola: tensóes e prazeres na prática pedagógica de professores de Ciências e Biologia. 2011. 140f. Dissertação (Mestrado em Educação) Universidade do Planalto Catarinense, Lages, 2011. 


\section{Resumo}

Processos de educação sexual em cursos de medicina: reflexóes sobre a construção do saber médico

Surge o artigo como resultado de pesquisas que identificam os profissionais da área da saúde como agentes procurados e autorizados para trabalhar a educação sexual no ambiente escolar. Estudos trazem indicadores de que várias comunidades escolares reconhecem nos médicos autoridade científica para fazer educação sexual. Apresenta-se uma retrospectiva sintética dessa formação, identificando nesses processos aspectos da construção do saber médico e alguns indicadores de sua transformação em autoridade legitimada por várias organizações educativas para realizar intencionalmente educação sexual. Esse entendimento naturalizouse em vários ambientes educativos formais e não formais. Texto reflete sobre a necessidade urgente do desvelamento da compreensão de docentes médicos e não médicos de cursos de medicina sobre a dimensáo humana da sexualidade e os reflexos desse entendimento em suas práticas pedagógicas.

Palavras-chave: Práticas pedagógicas em cursos de Medicina. Educação sexual emancipatória. Formação de professores.

\section{Abstract}

Sex education process in medicine courses: reflections on onstruction of medical knowledge

The article arises as a result of research that identified the health professionals as demanded and authorized agents to work sex education in the school environment. Studies present indicators that many school communities recognize the medical as the scientific authority to provide sex education. Presents a summary of this retrospective formation, identifying those aspects of the construction process of medical knowledge and some indicators of its transformation into legitimate authority by various educational organizations to intentionally make sex education. This understanding was naturalized in various formal and non-formal educational settings. Text reflects on the urgent need to unveil the understanding of medical and non-medical teachers of these courses about the human dimension of sexuality and the consequences of this understanding in their teaching.

Keywords: Pedagogical practice in medicine courses. Emancipatory sexual education. Teacher formation. 
